* Mestranda da Faculdade de Direito Milton Campos. Graduada em Direito na Universidade FUMEC. Email: sandralucia.adv@gmail.com.

** Doutora em Direito pela PUC Minas. Coordenadora do Núcleo de Pesquisa da Faculdade Milton Campos. Professora do Mestrado em Relações Econômicas e Sociais da Faculdade Milton Campos. Pesquisadora FAPEMIG e CNPq. Email: dralucianacsouza@gmail.com.

\section{Tecnologia e Trabalho na Era da INFORMAÇÃO}

\author{
TECHNOLOGY AND WorK IN THE \\ INFORMATION AGE
}

\section{Sandra Lúcia Aparecida Pinto* Luciana Cristina de Souza**}

Como citar: PINTO, Sandra Lúcia Aparecida; SOUZA, Luciana Cristina de. Tecnologia e trabalho na era da informação. Scientia Iuris, Londrina, v. 21, n. 3, p.99-124, nov. 2017. DOI: $10.5433 / 2178-8189.2017 \mathrm{v} 21 \mathrm{n} 3 \mathrm{p} 124$. ISSN: 2178-8189.

Resumo: O presente trabalho analisará, partindo da ruptura da era industrial e de seus contornos, quais os principais impactos gerados pela adoção de novas tecnologias no mercado, os efeitos da globalização mundial, incluindo o crescimento do desemprego, com o fechamento de postos de trabalho, a descentralização e ruptura da consciência coletiva do trabalhador, além das novas tendências, como o empreendedorismo e a informalização do trabalho. Considerando a política econômica neoliberal, fazem-se, no presente artigo, apontamentos sobre a postura do Estado frente às mudanças do mercado e seus reflexos, revelando-se a necessidade de adoção de políticas públicas para proteção do trabalho. 
Palavras-chave: Tecnologia. Globalização. Trabalho.

Abstract: This paper examines the rupture of the industrial era and their contours; the impacts of adopting new technologies within the marketplace; the effects of globalization - including increased unemployment and job foreclosure; the decentralization and breakdown of workers collective consciousness; in addition to new trends such as entrepreneurship and the informalization of work. Considering neoliberal economic policy, this paper comments on the State's attitude towards market changes and their effects, revealing the need to adopt public policies for job protection.

Keywords: Technology. Globalization. Job. 


\section{INTRODUÇÃO}

Que o mundo do trabalho não é o mesmo, não há dúvidas. As transformações sofridas, desde a revolução industrial, são altamente perceptíveis e extremamente relevantes. A evolução dos meios de produção, o fim da era do pleno emprego e a ruptura do domínio industrial, registram, de forma macro, as mudanças enfrentadas pelos atores das relações de trabalho. A globalização, a abertura dos mercados e o avanço tecnológico passam a reger, com novas notas, estas relações. Surge, então, a necessidade de uma análise mais aprofundada da atual realidade, como meio orientador e balizador de novas medidas e políticas garantidoras do Trabalho decente.

O presente trabalho tem por objetivo compreender as dimensões dos efeitos da globalização e da transformação tecnológica no mundo do trabalho, partindo da análise das antigas formas de produção, fortalecidas na era industrial, quando todas as estruturas que envolvem a vida do trabalhador giravam em torno do seu trabalho. Neste sentido, busca-se, por meio de uma contextualização histórica, delimitar a relevância do papel da grande indústria na vida dos seus trabalhadores, envolvendo, além deles próprios, sua família e a rotina da própria comunidade onde instalada.

Delimitada a realidade da era industrial e sua relevância na vida do indivíduo, passa-se à análise das mudanças provocadas pela globalização e pela transformação tecnológica neste cenário, traçando seus principais efeitos. Faz-se uma análise pormenorizada dos efeitos da tecnologia no mundo do trabalho e na vida do trabalhador. Verifica-se que, assim como a era da industrialização e do pleno emprego tiveram forte influência em todos os campos da vida do indivíduo, com participação 
em várias esferas, como a vida familiar, o lazer e a própria comunidade em que inserido, também o tem estes novos fenômenos. Pelas pesquisas realizadas é possível aferir os fortes impactos gerados e, ainda, as próprias tendências trazidas por esta nova realidade. $\mathrm{O}$ início do incentivo ao empreendedorismo, a migração do emprego formal para a informalidade e a falta de capacitação do trabalhador para atuar no novo mercado são amostras dos efeitos nefastos do descompasso vivido entre a era da informação e o mercado de trabalho.

Uma coisa, todavia, permanece imutável: a relevância do trabalho para o homem, como fator dignificante, garantidor da subsistência e da inserção social, sendo necessária, portanto, a adoção de medidas eficazes para sua proteção e promoção. Diante das tendências de mercado e, ainda, das práticas neoliberais, nota-se a crescente desresponsabilização do estado quanto à realidade dos trabalhadores face às diversidades consequentes da globalização e das novas tecnologias. Entretanto, percebe-se a crescente necessidade da adoção de políticas públicas garantidoras da empregabilidade no novo cenário existente como mecanismo de sustento e garantia de qualidade de vida para muitas famílias, notadamente aquelas que integram os estratos mais pobres da economia nacional, pois a automação desregulamentada, por exemplo, pode aumentar o desemprego entre os que têm maios dificuldade de acesso à capacitação tecnológica.

Não raro essas pessoas são, posteriormente, deixadas "à própria sorte", como alerta a pesquisa de Meirelles e Athayde (2014, p. 73, 76) sobre as favelas brasileiras:

Em anos recentes, a favela tem se tornado um qualificado laboratório na incubação 
de novos negócios. Mas, por quê? O morador da comunidade, durante longo tempo obrigado a se virar sozinho, desenvolveu habilidades e vocações para a produção e o comércio. [...] Muitos dos pequenos empreendimentos nessa área derivam do fomento dos bancos comunitários, que hoje são mais de cinquenta no Brasil. [...] Operando sob o princípio da economia solidária, no campo do microcrédito, a organização estimula a produção e o consumo, gerando trabalho e renda para a comunidade. [...]. Um estudo do Sebrae levado a cabo em dezoito comunidades exibe o perfil médio do empreendedor. Ele é mulher, tem mais de 40 anos e pouca intimidade com a internet. Uma das tarefas urgentes dos técnicos da entidade é gerar soluções de aprendizado para que esses construtores de negócios utilizem as ferramentas digitais de comunicação.

Logo, a realidade econômica das comunidades de favelas no Brasil é uma das tentativas da população de sobreviver à má gestão do processo de participação do capital e do trabalho no mercado global. Sem políticas públicas adequadas de proteção ao trabalhador, a informalização - inclusive a criação de instituições financeiras próprias, menos especulativas - torna-se o meio eficaz e muitas vezes único para a subsistência.

\section{OS EFEITOS DA GLOBALIZAÇÃO E DATRANSFORMAÇÃO TECNOLÓGICA}

Outro efeito maléfico da globalização mundial da economia, além do desemprego, é a desconstrução das "identidades" sociais. Por exemplo, as cidades operárias, conhecidas no período de seu maior desenvolvimento como cidades-polo de outras menores e menos ricas, 
eram as grandes responsáveis pela geração de emprego e renda para as pequenas e médias regiões dos estados mais industrializados do Brasil. Todavia, nas recentes décadas, elas se viram privadas de inúmeros postos de trabalho devido aos efeitos do fenômeno da globalização, cuja abrangência não se restringe ao campo econômico.

Nessa nova economia de mercado o operário industrial sofreu com a desconstrução da sua identidade pelas transformações sofridas pelas categorias profissionais quanto ao modo de se relacionar socialmente. As demandas sociais são diferentes das de outrora e há maior negociação dos direitos e prerrogativas adquiridos no Estado do Bem-Estar Social (mesmo que essa modalidade de Estado tenha se apresentado sob tipos variados na América Latina, diferentemente dos Estados Unidos da América e da Europa). Os movimentos sindicais começaram a reformular sua linha de atuação, uma vez que a ausência do Estado grande e forte remete à sociedade civil boa parte das discussões políticas anteriormente efetivadas pelos governos junto aos setores privados.

A associação da identidade do operário com a da empresa se fragmentou e não foi substituída por outra correlação de natureza semelhante. Em diversos centros urbanos se podia observar um "viver para a indústria" que não existe mais com a mesma intensidade. Anteriormente, desde a alfabetização os filhos dos operários, que muitas vezes estudavam em escolas dos Serviços “S” (SENAI, SENAT, etc.), até o ensino médio voltado para a aquisição de uma profissão técnica, de modo geral a vocação para o trabalho parecia uma espécie de hereditariedade nas cidades que dependiam mais de suas indústrias e nesses meios urbanos, portanto, os efeitos da globalização e das transformações tecnológicas foram sentidos mais fortemente.

Por exemplo, era comum os departamentos de recursos humanos 
contratarem sob indicação de empregado, o qual respondia com seu próprio emprego, não raro, pelos maus serviços prestados por seu indicado. Devido a isso, optava-se por indicar apenas parentes ou amigos próximos. Embora essa prática ainda persista em alguns lugares, os laços que ligam as pessoas de uma mesma empresa já não são tão próximos e pessoais, haja vista a rotatividade de recursos humanos que atualmente acontece em face da precarização do trabalho. Para os empregados em geral, vale mais adquirir experiências em diversos lugares do que manter uma relação de décadas com uma única empresa.

Por isso as mudanças provocadas pelo período atual modificaram tanto a relação entre o ambiente de trabalho e familiar, o que afetou a definição da identidade pessoal e laboral de muitas pessoas. Além disso, há um problema intergeracional em muitas empresas, pois empregados cuja identidade pessoal e organizacional foi formada no período préglobalização e sem a intervenção de tantas tecnologias digitais enfrentam, frequentemente, dificuldade na interação diária no ambiente laboral com a geração mais jovem que, além de não se espelhar nos valores "tradicionais", também possui uma personalidade completamente afetada por sua criação em um meio social no qual a internet era uma realidade acessível desde cedo. O modo de pensar e agir das novas gerações é moldado pelo pensamento racional conectado em rede e em que cada indivíduo está muito mais próximo de seus "contatos" do que da identidade operário-indústria-famílias.

Assim, uma nova espécie social apareceu no cenário mundial nos primórdios do século XXI, a qual já vinha se formando no entardecer do século anterior. Esse crepúsculo da "família ao redor da indústria" é gradativamente substituído por modelos mais individualizados e descentralizados de trabalho, resultante da chamada Era da Informação. 
Entende-se por Era da Informação e do Conhecimento a configuração de um padrão sócio-técnicoeconômico, hoje emergente, em que as atividades humanas estão centralmente baseadas e organizadas em torno das atividades de geração, recuperação e uso de informações e conhecimento (LASTRES; ALBAGLI, 1999, p. 291).

“A sociedade da informação não é um modismo. Representa uma profunda mudança na organização da sociedade e da economia, havendo quem a considere um novo paradigma técnico-econômico" (TAKAHASHI, 2000, p. 5).

A própria alteração desse "lugar de trabalho" do operariado, a grande indústria, para um "lugar de consumo" é reflexo nítido da nova organização social denominada informacional. $\mathrm{O}$ espaço físico do exercício do trabalho fixava uma série de comportamentos sociais da população ao redor. Formaram-se bairros e centros de formação em técnicas de manuseio das máquinas; o governo local disponibilizou recursos e serviços públicos para estruturar esse modelo de vida social, com regulamentações específicas inclusive. Vários dos clubes recreativos existentes, que representavam quase a única modalidade de lazer oferecida aos operários e suas famílias, pertenciam às indústrias ou a associações vinculadas a estas. Alguns deles fecharam, outros continuam a existir só que em outros moldes. As escolas mantidas pelos serviços de apoio à indústria hoje já não são gratuitas, posto que perderam diversos subsídios públicos e investimentos privados. Elas ministravam, em muitos casos, aulas de teatro e música para os alunos. Logo, com a fragmentação dos vínculos com o trabalho, por sua base econômica 
dependente direta do mercado global, houve a fragmentação de outras relações sociais deles dependentes. Nesse ínterim, o trabalhador viu-se submetido a um processo de adaptação forçada. Sua empregabilidade ${ }^{1}$ foi dissolvida por valores flexíveis e mutáveis, não raro, cuja finalidade era servir à indústria de conteúdo, à produção de conhecimento. Essa mudança de perfil do operariado alterou sua identidade coletiva. Seu poder de unir-se a iguais para a defesa de sua posição no mercado também sofreu perdas irreparáveis com a dispersão das forças produtivas provocada pela produção em rede. Mesmo localmente, nas fábricas, a divisão do trabalho diversificou-se. Não existe mais uma solidariedade entre as funções especializadas dos indivíduos tão intensamente quanto no passado, pois parte dessas mesmas funções hoje são compartilhadas ou codependentes de atividades efetuadas por máquinas: computadores, controladores e robôs.

E outras mudanças impactaram na vida social, pois: "as transformações provocadas pela tecnociência moderna acabaram, com o tempo, extrapolando o registro das atividades produtivas e, assim, começaram a influir na existência cotidiana" (RÜDIGER, 2013, p. 12). Por exemplo, o trabalho imaterial se expandiu como aglutinação do trabalho manual com o intelectual, valorizando modelos gerenciais. O empreendedorismo cresceu como tentativa de renda das sociedades modernas, especialmente na classe média. A desmaterialização do trabalho pelo consumo virtual, conjugada à propulsão da técnica nos meios de comunicação desenvolveu amplamente facções do setor de serviços vinculadas à produção do conhecimento. Pequenas e médias empresas ampliaram seus negócios, especialmente na área de informática,

1 Como "empregabilidade" se entende a capacidade-expectativa do indivíduo de inserir-se no mercado de trabalho.

SCIENTIA IURIS, Londrina, v.21, n.3, p.99-124, nov.2017 DOI: 110.5433/2178-8189.2017v21n3p99 
mas isso não provocou o crescimento, no Brasil, da mão de obra especializada autônoma.

Diante disso, percebe-se a contração ainda maior que sofre o mercado de trabalho diante da tendência à substituição do empregado formal pelo microempreendedor individual - MEI (empregados chamados de "associados" ou "colaboradores") adaptado à Era do Conhecimento, o que acirrou o intenso processo de exclusão de inúmeros trabalhadores excedentes e desqualificados do mercado formal. Estes dois desafios, novo perfil das relações de trabalho e aptidão tecnológica, devem ser objeto de políticas públicas de empregabilidade urgentemente, visto que é preciso preservar postos de trabalho e, também, oferecer qualificação profissional. Pode-se, então, afirmar que a economia do conhecimento está, efetivamente, estabelecendo novas bases para as relações de trabalho e essa análise, no caso brasileiro, há de levar em conta não somente o papel do Estado mas, igualmente, o fato de que a empregabilidade tem se concentrado nas pequenas e médias empresas, notadamente por serem:

a) as maiores empregadoras de mão de obra nacionais (SEBRAE, 2016);

b) dedicadas ao setor de serviços primordialmente (GARBIN, 2016);

c) beneficiárias de um sistema mais flexível de produção.

Porém, a realidade social brasileira não permite, ainda, que se tenham expectativas tão otimistas. Existem, sim, grandes veios de empreendedorismo na área de informática, que todavia são de acesso ainda restrito para a maioria da população, insuficientemente qualificada e economicamente distante dos recursos tecnológicos. Além disso, o processo de globalização dos mercados, nesse contexto, impôs ao ritmo do relógio industrial a dinâmica das supervias de dados. O tempo real é 
substituído pelo tempo virtual, especialmente quando em atividades de home office ou teletrabalho.

A informação transmite-se, renova-se, constrói-se e dura o tempo do clique do mouse, o que nos exige a elaboração de novos critérios de confiabilidade e segurança, assim como o conhecimento via rede mundial de comunicação expande-se em milhares de bits por segundo. E esse processo de mudança social da noção de tempo e de trabalho em decorrência das novas tecnologias, que é denominado como fase dromocrática por Eugênio Trivinho (2005), pode ser extremamente nocivo ao ser humano, configurando verdadeira forma de violência.

O conceito de dromocracia teve, no âmbito das ciências humanas e sociais, a sua gestação e fundação crítica na obra de Paul Virilio. Em Velocidade e politica, Virilio (1977) lança, senão as bases, ao menos as sinalizações teóricas fundamentais para a compreensão da história e dos processos políticos e sociais pelo prisma do vetor dromológico. Dromos, prefixo grego que significa rapidez [...] A velocidade tecnológica, quando urdida em estrutura dinâmica universal, cria, como que de forma endogenamente autônoma, a partir das pressões materiais, simbólicas e imaginárias da organização do trabalho e do lazer, as suas próprias demandas recorrentes. A nova lógica da desigualdade gira em torno do imperativo da dromoaptidão propriamente cibercultural [...] como capital simbólico necessário para a manifestação individual, grupal, empresarial e institucional no social em rede (TRIVINHO, 2005, p. 63, 72).

Logo, hoje, já estamos atrasados em aquisição de saber antes mesmo de abrirmos os olhos de manhã. E esta socialização da produção 
resulta, evidentemente, das atuais relações de consumo desenvolvidas via web por meio das quais o consumidor produz: “A transação é o produto." (LASTRES; ALBAGLI, 1999, p. 278). O setor de prestação de serviços é o que mais cresce na Era do Conhecimento, todavia com uma clara especificidade. Não é qualquer modalidade de serviço, mas, em evidência, aquelas que possam ser produzidas e consumidas via internet, primordialmente. A informatização da linha de produção, dos métodos educacionais e das próprias relações sociais demanda um saber tecnológico específico mesmo para o indivíduo comum (dromoaptidão) e cria, ainda, a expectativa - faticamente ainda não alcançada - de um acréscimo da oferta de vagas no setor de serviços proporcional ao fechamento dos postos de trabalho da indústria convencional, notadamente na construção de "ferramentas" que atendam aos usuários de sistemas computadorizados.

Esse pressuposto de que apenas haveria uma mudança de colocação do operário, transformado em prestador de serviços, é incorreto, contudo. Não há uma "lei" de mercado ou social que possa comprovar essa premissa, tampouco explicar o seu acontecimento enquanto fenômeno social, pois o que na realidade se observa é o aumento das vagas apenas para pessoas extremamente qualificadas nessas novas tecnologias (os especialistas dromoaptos) e com inglês fluente, idioma padrão da sociedade globalizada. Isso significa que, na prática, muitos têm sido os obstáculos reais à implementação do inciso XXVII, do art. $7^{\circ}$, da Constituição da República Federativa do Brasil de 1988: "proteção em face da automação, na forma da lei” (BRASIL, 1988). ${ }^{2}$

2 Em 1984, mesmo antes da Constituição Cidadã (1988), foi criada a Política Nacional de Informática, pela Lei n. 7232, que previa em seu at. $2^{\circ} \mathrm{o}$ "ajuste continuado do processo de informatização às peculiaridades da sociedade brasileira" (inciso V) e a garantia dos "níveis de emprego na automação dos processos produtivos" (inciso X). 
Em decorrência dessa realidade, a infraestrutura de informações tornou-se o ponto central de discussões políticas, em virtude de sua dependência em relação ao novo meio de suporte tecnológico adequado para a sua expansão. Existe, na verdade, uma corrida constante nas áreas de hardware e software com o intuito de construir um ambiente no qual o conhecimento produzido em rede possa se difundir cada vez mais e com maior velocidade (TRIVINHO, 2005, p. 72). O próprio desejo constante de novidade que caracteriza as relações de consumo pós-modernas, e cresce seu poder de influência sobre o mercado a cada dia, conduz o saber tecnológico e científico a saciá-lo, movimentando um mercado mundial em que o capital é virtual, os relacionamentos são por avatares - o que não implica nenhuma dificuldade em que sirva para ambiente de negócios, haja vista a comunidade virtual Second Life - e a legislação do Estado muito pouco ainda consegue regular.

Até que ponto as relações de trabalho podem se deteriorar é também uma preocupação. Mantida a tendência atual, alguns estudos apontam que, no início do novo século, apenas $25 \%$ da população economicamente ativa será de trabalhadores permanentes, qualificados e protegidos pela legislação, 25\% dos trabalhadores deverão estar nos chamados segmentos informais, poucos qualificados e desprotegidos, assim como 50\% dos trabalhadores poderão estar desempregados ou subempregados, em trabalhos sazonais, ocasionais e totalmente desprotegidos pela legislação. Cada vez mais se exige dos trabalhadores contínua atualização e desenvolvimento de habilidades e competências, de modo a atender aos novos requisitos técnicoeconômicos e a aumentar sua empregabilidade (TAKAHASHI, 2000, p. 21). 
Em seu livro, Lastres e Albagli (1999) ressalta essa problemática da ausência de regulamentação legal e de políticas públicas próprias da nova sociedade informacional. A reorganização dos atores sociais e a reformulação de seus papéis nesse contexto sugere uma nova modalidade de articulação da sociedade civil, posto que o Estado tem seu poder de proteção às prerrogativas dos cidadãos enfraquecido no contexto econômico atual. As organizações não governamentais há certo tempo vêm preenchendo esse espaço, sem contudo evitar críticas profundas a esta ausência governamental quanto ao dever de garantir a satisfação de seus cidadãos em suas necessidades primordiais, entendendo-se estas como "tudo aquilo que interfere, de forma direta ou indireta, no plano de vida da pessoa ou do grupo em relação às suas atividades essenciais, inviabilizando-as ou tornando-as insuficientes" (GUSTIN, 1999, p. 27).

A concentração de capital, a divisão do trabalho maximizada pela competição tecnológica e a divulgação de valores individuais para favorecer o fenômeno do consumo colaboram para a configuração social de uma cultura na qual se tornam fatos comuns a especulação financeira, a flexibilização das relações de emprego e o enfraquecimento dos laços sociais. No campo das relações de trabalho, a competição acirrada divide esforços na busca por verbas como, por exemplo, as dos fundos de amparo ao trabalhador, voltadas à qualificação do operário para o mercado. $\mathrm{O}$ empreendedorismo cresce como via de sobrevivência ao fechamento dos postos de trabalhos tradicionais, mas não em ritmo e modelo adequados em virtude do distanciamento da população brasileira em relação ao acesso ao conhecimento. E, considerando-se que o campo da produção imaterial é um dos que mais cresce (MERCADO..., 2016) 
- softwares, consumo cultural, músicas para download, tags, podcasts, blogs, publicidade, e tudo o mais que pode ser consumido enquanto informação - o espaço de atuação do profissional que não domine tais conteúdos reduz-se drasticamente.

Em razão desse quadro, há a necessidade hoje de se criar novas metodologias educacionais para a sociabilidade digital. Infelizmente, constata-se na realidade brasileira um descompasso entre os processos de inovação tecnológica e os de aprendizado sobre essa tecnologia, inviabilizando o acesso ao conhecimento que a própria norma constitucional brasileira determina como imprescindível para a atuação profissional: "é livre o exercício de qualquer trabalho, ofício ou profissão, atendidas as qualificações profissionais que a lei estabelecer" (art. 5’, XIII, Constituição da República, de 1988). Este se torna um obstáculo sério à prática empreendedora que se quer implantar no Brasil, seja como saída para o desemprego ou seja como resposta ao desenvolvimento econômico esperado para o novo milênio com respaldo nos art. 3. ${ }^{\circ}$ e 170 da mesma Carta Magna.

A educação profissional, portanto, necessita ser ampliada por meio de políticas públicas efetivas para a correção desse quadro, não apenas como mecanismo de ingresso no mercado de trabalho formal por meio da adequada qualificação profissional, como dispõem os art. 205 e 214, IV, da Carta Constitucional de 1988, mas principalmente porque, não sendo possível a absorção de toda a mão de obra pelo mercado, é direito do indivíduo a autonomia econômica para empreender com chances de sucesso. Não podemos cometer o mesmo equívoco dos liberais franceses que apenas asseguraram a liberdade formal, sem comprometimento com a materialidade da vida em sociedade. 
Considerando isso, podemos dizer que as exclusões digital e econômica são duas grandes frentes de batalha nesse cenário globalizado. $\mathrm{O}$ analfabetismo virtual, verbi gratia, prejudica a compreensão e interpretação das informações que circulam na rede mundial, bem como o acesso a postos de trabalho mais qualificados. Em razão disso, o indivíduo vê-se tolhido e até impedido de fazer leituras próprias do mundo e da sua realidade local.

Convém distinguir o caso das economias industriais, onde domina o trabalho assalariado, do de outras economias onde domina, ainda em grande escala, o trabalho independente ou informal. De fato, nas sociedades assalariadas que se desenvolveram ao longo do século XX, a partir do modelo industrial, a substituição do trabalho humano pelas máquinas tornou-o cada vez mais imaterial e acentuou o caráter cognitivo das tarefas, mesmo na indústria, assim como a importância dos serviços na atividade econômica.

O futuro dessas economias depende, aliás, da sua capacidade de transformar o progresso dos conhecimentos em inovações geradoras de novas empresas e novos empregos. Aprender a fazer não pode, pois, continuar a ter o significado simples de preparar alguém para uma tarefa material bem determinada, para fazê-lo participar do fabrico de alguma coisa. Como consequência, as aprendizagens devem evoluir e não podem mais ser consideradas como simples transmissão de práticas mais ou menos rotineiras, embora estas continuem a ter um valor formativo que não é de se desprezar (DELORS,1998, p. 93, grifo nosso).

Indaga-se, então, se haveria um determinismo tecnológico (AUGUSTO, 2009, p. 311). Estaríamos submetidos a um "maquinismo" 
(RÜDIGER, 2013, passim) diante do qual caberia ao ser humano apenas se adaptar - ou criar suas próprias alternativas como as comunidades de favelas têm feito?

Infelizmente, da forma como tal processo social está sendo imposto, parece que sim. Essa dinâmica da relação laboral na Era Informacional (ou Digital) parece se delinear cada dia mais fortemente em desfavor do elo mais fraco economicamente, ao mesmo tempo em que valores como dromocracia e dromoaptidão vão, gradativamente, impondo novas diretrizes quanto ao modo pelo qual o trabalho deva ser desempenhado:

As novas tecnologias, ao romperem com a lógica linear requisitando uma lógica pautada na rede hipertextual e no estabelecimento de múltiplas conexões (Lévy, 2000), mostraram que os novos processos de trabalho também reconfiguraram as profissões [...]. Em pouco tempo, o trabalho e sua organização passaram por reformulações profundas que favoreceram a configuração de um novo paradigma respaldado por ideias muito diferenciadas como, por exemplo, a desmaterialização da produção e da prestação de serviços. [...] O stress no contexto laboral aparece travestido de estímulo para realização, muito mais do que como sinônimo de doença ocupacional. $\mathrm{O}$ discurso recorrente entre os trabalhadores da contemporaneidade concentra ordens para se "administrar" situações estressoras, muito mais do que para eliminá-las, já que tal tarefa se apresenta com hercúlea (KANAN; ARRUDA, 2013, p. 586-589).

\section{O DIREITO E APROTEÇÃO DO TRABALHO NA ERA DIGITAL}


Frente a esse cenário de tentativa espúria de justificar os problemas advindos com o avanço tecnológico desprovido de uma preocupação mais séria com a qualidade do trabalho para o ser humano se observa que a disponibilização das novas tecnologias para os cidadãos exige uma atuação intensa do Estado na regulamentação dos direitos fundamentais: "art. 23 - É competência comum da União, dos Estados, do Distrito Federal e dos Municípios: V - proporcionar os meios de acesso à cultura, à educação e à ciência." (Constituição da República, de 1988). A mera aquisição de know-how tecnológico pelo Brasil é insuficiente para sanar essas questões sem estar acompanhada de um grande investimento em políticas públicas na área educacional e em qualificação profissional. É preciso atacar problemas sérios, como a baixa escolaridade da população brasileira, que representa um sério obstáculo à modernização e à inclusão dessas pessoas no mercado de trabalho, posto que na sua maioria estão engajadas em atividades manuais não especializadas, por isso sendo mais severamente atingidas pelo desemprego atual. Então, como aproveitar em funções mais específicas e técnicas operários dos "tempos modernos" chaplinianos? Como evitar que a pressão da competição globalizada e os avanços tecnológicos continuem causando efeitos perversos aos trabalhadores no Brasil?

Esse cenário evidencia o quanto são imprescindíveis políticas públicas específicas que atuem com maior firmeza no sentido de protegerem a empregabilidade (o ingresso e a continuação do posto de trabalho), consoante dispõe a Lei Fundamental de 1988, contra os riscos envolvidos em um processo de automação e, também, de migração do modelo industrial para as tecnologias ligadas à internet e outras da Era Informacional. As medidas protetivas existentes são, ainda, insuficientes para estabelecer essa proteção em decorrência do modo como tem agido 
o Estado para solucionar as controvérsias entre indústrias, nova elite econômica ligada à produção digital e empregados. Conforme explica Frúgoli Júnior:

$\mathrm{Na}$ esteira da desresponsabilização do Estado e do desmanche das políticas públicas e dos direitos sociais em curso no país ao longo dos anos 1990, o discurso de autonomia popular em relação ao poder público revela alguns impasses. As práticas e experiências de autonomia e de solidariedade dos movimentos sociais encontram, depois de duas décadas, sua face perversa e seu avesso [...] (RIZEK, 2006, p. 399-400).

Essa desresponsabilização do Estado, traço bem característico de políticas econômicas neoliberais, segundo Sônia M. Draibe (1993, p. 97), contribui para agravar a já precária situação dos trabalhadores no mercado globalizado, visto que o neoliberalismo defende a retração da atuação estatal na área dos direitos sociais. Estas políticas, no ensinamento de Teresa Sá (2010), constituem um modelo social permeado de incerteza e de risco, o qual é ainda mais comprometido pela concepção liberal e o fato de muitos segmentos da sociedade perceberem tal situação como um quadro "algo dado" e impassível de mudança. E, assim, inserido neste contexto, o trabalhador passa a ser o responsável pela sua própria empregabilidade, eximindo o estado. Entretanto, como consequência desta concepção liberal, o cenário de desemprego e queda no desenvolvimento permanecem, ante a fragilidade da atuação isolada de cada cidadão.

Os reflexos do progresso tecnológico no mundo do trabalho e a necessidade de adoção de medidas para sua proteção também são alvo de 
preocupação dos organismos internacionais. Neste sentido, a Organização Internacional do Trabalho (OIT), na $105^{\mathrm{a}}$ Conferência Internacional do Trabalho realizada em 2016, em Genebra, editou o Relatório VI que trata sobre a promoção da justiça social numa globalização justa. No documento, esse organismo internacional (ORGANIZAÇÃO INTERNACIONAL DO TRABALHO, 2016, p. 5) registra a preocupação com os efeitos da tecnologia no campo do trabalho, mas também ressalta as possibilidades por ela trazidas:

O mundo do trabalho encontra-se igualmente em mutação como resultado do rápido progresso tecnológico. A microinformática e as tecnologias de informação, os progressos nos domínios da robótica, software e inteligência artificial e a multiplicidade de serviços disponíveis na Internet mudaram o modo de produção e fornecimento de bens e serviços. Estas inovações fortaleceram as ligações entre a indústria transformadora, o setor da agricultura e o setor dos serviços, afetando inevitavelmente a organização do trabalho. Como o desaparecimento de trabalhos rotineiros, têm vindo a aparecer novos empregos na economia do conhecimento, na economia verde e na economia de cuidados, tanto em países em desenvolvimento como industrializados. Segundo as estimativas da OIT, a transição para uma economia mais verde poderá gerar entre 15 a 60 milhões de novos postos de trabalho a nível mundial nas próximas décadas. Os tipos de trabalho relacionados com a digital facilitam a conexão entre trabalhadores e empregadores e oferecem flexibilidade, mas também trazem desafios no sentido de garantir condições de trabalho digno. Sem contratos formais, estas novas modalidades podem implicar horários de trabalho excessivos e proteção social reduzida. Devido à natureza descentralizada destes empregos, 
torna-se mais difícil aos trabalhadores organizaremse e exercerem o seu direito à negociação coletiva (ORGANIZAÇÃO INTERNACIONAL DO TRABALHO, 2016, p. 5).

Diante das mudanças experimentadas no mercado de trabalho - as quais podem ser verificadas no banco de dados da Organização Internacional do Trabalho -com a criação de novas formas de relação, descentralizadas, dificultando organização do trabalhador em sindicatos, e, também, a atuação destes em busca da sua proteção, torna-se mais clara a necessidade de atuação estatal, não se podendo sucumbir às práticas econômicas neoliberais. Nesse sentido é muito importante, também, a "adoção preferencial de tecnologias, padrões e formatos abertos e livres" que facilitem o acesso dos grupos mais pobres ao conhecimento disponível na internet (BRASIL, 2014), pois por meio deles seria viável ofertar-se cursos de capacitação e instrumentos ágeis de comunicação e inserção digital daquela parcela da população que corre o risco de ser a mais excluída com a globalização atual e com o forte impacto da rápida "evolução" dos meios tecnológicos.

\section{CONCLUSÃO}

Como visto, as constantes evoluções pelas quais passaram o mundo do trabalho nos últimos anos foram fortemente influenciadas pela globalização ou mundialização da economia e pelos avanços tecnológicos. Este cenário, com o passar do tempo, sofreu graves mudanças que resultaram no fim da era do pleno emprego e no início da era da informação, marcada pelo surgimento de modelos mais individualizados 
e descentralizados de trabalho. Como efeito da globalização mundial, houve o aumento drástico do desemprego, surgindo, então, a necessidade da criação de novas formas de trabalho. Esse fenômeno, porém, obrigou o trabalhador a um processo de adaptação forçada, diante da brusca ruptura com os antigos modelos. Os modelos de produção, agora dotados de tecnologias mais avançadas, sofrem alterações. Algumas funções são completamente absorvidas, outras, passam a ser compartilhadas ou codependentes de atividades efetuadas por máquinas, fomentando o desemprego estrutural. A própria noção do coletivo, que teve papel fundamental na luta dos trabalhadores por seus direitos, se dispersa, diante das novas formas descentralizadas de produção.

A vida social dos trabalhadores também sofre os impactos dessas mudanças. Sua rotina, antes marcada pela realidade da própria indústria onde trabalhava, a qual exercia forte influência, inclusive na comunidade em que inserida, passa a ser pautada na desmaterialização do trabalho pelo consumo virtual. $\mathrm{O}$ trabalhador passar a ser o único responsável pela sua empregabilidade, necessitando adaptar-se, rapidamente, à nova realidade. As formas de trabalho também apresentam alterações substanciais. O emprego formal perde espaço para a informalidade e o incentivo ao empreendedorismo cresce, provocando o crescimento da mão de obra especializada autônoma, seguindo a tendência de substituição do empregado pelo microempreendedor individual, também chamado de associado ou colaborador.

Esta tendência, no entanto, só absorve aqueles trabalhadores qualificados, preparados para as novas tecnologias e adaptados ao ambiente globalizado. A dromocracia exige do indivíduo, cada vez mais, a capacidade de rápida adaptabilidade, capacitação e aquisição de conhecimento, provocando a exclusão daqueles insuficientemente 
qualificados. Emerge a necessidade de adoção de medidas protetivas e garantidoras da empregabilidade destes trabalhadores, agora afastados do mercado pelas suas condições. As mudanças no mundo do trabalho, assim como outrora impulsionaram a sua regulamentação, da forma que ainda persiste, necessitam ser novamente avaliadas, para reformulação dos papéis dos atores sociais. Torna-se necessário que o Estado, imbuído do seu poder de proteção às prerrogativas dos cidadãos enfraquecidos no contexto econômico social.

Neste compasso, a adoção de políticas públicas voltadas para a qualificação do profissional, como preceitua a própria Carta Cidadã de 1988, é medida de extrema relevância, tanto para manutenção da empregabilidade do indivíduo, garantindo o acesso aos postos de trabalho existentes, quanto para possibilitar o exercício do empreendedorismo, já que, com a implantação de novas tecnologias, os postos de trabalho tornaram-se insuficientes para absorção de toda a mão-de-obra existente. O próprio incentivo ao empreendedorismo necessita de melhor avaliação para sua prática, com adoção de medidas efetivas garantidoras da inserção do cidadão no cenário globalizado, por intermédio de sua capacitação para atuação na era digital.

É preciso lembrar, ainda, que a descentralização do trabalho retira do trabalhador uma de suas principais forças reativas, a atuação coletiva, o que torna ainda mais necessária uma ação afirmativa por parte do Estado, com o objetivo de garantir os próprios preceitos constitucionais da livre iniciativa e dos valores sociais do trabalho. Assim, não obstante a postura de desresponsabilização do Estado marcada pelas políticas econômicas neoliberais, que defendem a retração da atuação estatal na área dos direitos sociais, assiste-se, cada vez mais, a necessidade da adoção de medidas hábeis a reverter o cenário vivenciado pelo mundo 
do trabalho na atualidade.

Torna-se imperiosa a revisão das medidas protetivas do trabalho, face a nova realidade da era digital, por meio de uma reanálise integral do contexto atual, abrangendo os contornos do mercado de trabalho formal e todas as novas formas de atuação doravante aplicadas. É preciso formalizar estratégias que garantam a continuidade do crescimento tecnológico, a competitividade nacional no cenário globalizado, com foco, também, na parcela da população despreparada, pouco qualificada e ainda enraizada nos antigos modos de produção.

\section{REFERÊNCIAS}

AUGUSTO, André Guimarães. A dessubjetivação do trabalho: o homem como objeto da. Revista de Economia Contemporânea, Rio de Janeiro, v. 13, n. 2, p. 309-328, maio/ago. 2009.

BRASIL. Constituição (1988). Constituição da República Federativa do Brasil de 1988. Disponível em: <http://www.planalto.gov.br/ ccivil_03/constituicao/constituicaocompilado. htm>. Acesso em 23 jan. 2017.

BRASIL. Lei $\mathbf{n}^{\mathbf{0}}$ 12.965, de 23 de abril de 2014. Estabelece princípios, garantias, direitos e deveres para o uso da Internet no Brasil. Disponível em: <http://www.planalto.gov.br/ ccivil_03/_ato2011-2014/2014/lei/ 112965.htm>. Acesso em: 30 jan. 2017.

DELORS, Jacques et al. Educação: um tesouro a descobrir. São Paulo: Cortez, 1998.

DRAIBE, Sônia M. As políticas sociais e o neoliberalismo: reflexões suscitadas pelas experiências latinoamericanas. Revista da USP, São Paulo, n. 71, p. 86-101, mar./maio 1993. 
GARBIN, Daiana. Mercado de TI é um dos setores que não pararam de contratar no Brasil. G1, Jornal da Globo, São Paulo, 13 de fevereiro de 2016. Disponível em: <http://g1.globo.com/jornal-da-globo/ noticia/2016/02/mercado-de-ti-e-um-dos-setores-que-nao-pararam-decontratar-no-brasil.html>. Acesso em: 2 set. 2016.

GUSTIN, Miracy Barbosa de Souza. Das necessidades humanas aos direitos: ensaio de sociologia e filosofia do direito. Belo Horizonte: Del Rey, 1999.

KANAN, Lília Aparecida; ARRUDA, Marina Patrício de. A organização do trabalho na era digital. Estudos de Psicologia, Campinas, v. 30, n. 4, p. 583-591, 2013.

LASTRES, Helena Maria Martins; ALBAGLI, Sarita (Org.). Informação e globalização na era do conhecimento. Rio de Janeiro: Campus, 1999.

MEIRELLES, Renato; ATHAYDE, Celso. Um país chamado favela: a maior pesquisa já feita sobre a favela brasileira. São Paulo: Gente, 2014.

MERCADO de TI deve crescer 3\% em 2016 no Brasil, aponta estudo da Abes e do IDC. Época, Negócios, 06 de junho de 2016. Disponível em: $<$ http:/epocanegocios.globo.com/Tecnologia/noticia/2016/06/epocanegocios-mercado-de-ti-deve-crescer-3-em-2016-no-brasil-apontaestudo-da-abes-e-do-idc.html>. Acesso em 02 de setembro de 2016.

ORGANIZAÇÃO INTERNACIONAL DO TRABALHO - OIT. Promover a Justiça Social. Genebra, 2016. Relatório VI. Disponível em <http://www.ilo.org/public/portugue/region/ eurpro/lisbon/pdf/ cit105_relatorio_vi_pt.pdf $>$. Acesso em: 30 jan. 2017.

RIZEK, Cibele Saliba. Mutirões autogeridos: construindo e desconstruindo sociabilidades. In: FRÚGOLI JÚNIOR, Heitor; ANDRADE, L.uciana Teixeira; PEIXOTO, Fernanda Aréas. As cidades e seus agentes: práticas 
e representações. São Paulo: EDUSP, 2006. p. 377-401.

RÜDIGER, Francisco. As teorias da cibercultura: perspectivas, questões e autores. Porto Alegre: Sulina, 2013.

SÁ, Teresa. "Precariedade" e "trabalho precário": consequências sociais da precarização laboral. Revista de Sociologia Configurações, Braga, n. 7, 2010. Disponível em: $<$ http://configuracoes.revues.org/203>. Acesso em: 14 fev. 2017.

SEBRAE. Pequenos negócios contratam mais que grandes em 2015. 2016. Disponível em: <http:/www.agenciasebrae.com.br/sites/asn/uf/ NA/pequenos-negocios-contrataram-mais-que-grandes-em-2015,ef61b8 5844cb5510VgnVCM1000004c00210aRCRD> Acesso em: 2 set. 2016.

TAKAHASHI, Tadao (Org.). Sociedade da Informação no Brasil: livro verde. Brasília: Ministério da Ciência e Tecnologia, 2000.

TRIVINHO, Eugênio. Introdução à dromocracia cibercultural: contextualização sociodromológica da violência invisível da técnica e da civilização mediática avançada. Revista FAMECOS, Porto Alegre, v. 12, n. 28 , p. $63-78,2005$.

Como citar: PINTO, Sandra Lúcia Aparecida; SOUZA, Luciana Cristina de. Tecnologia e trabalho na era da informação. Scientia Iuris, Londrina, v. 21 , n. 3 , p.99-124, nov. 2017. DOI: $10.5433 / 2178-8189.2017 \mathrm{v} 21 \mathrm{n}$ 3p124. ISSN: $2178-8189$.

Recebido em 14/02/2017

Aprovado em 06/09/2017 